\title{
Capability of ground fertiliser placement when spread from fixed wing aircraft
}

\author{
S.E. $\mathrm{CHOK}^{1}$, M.C.E. GRAFTON ${ }^{1}$, I.J. YULE ${ }^{1}$ and M.J. MANNING ${ }^{2}$ \\ ${ }^{I}$ New Zealand Centre for Precision Agriculture, Institute of Agriculture and Environment, Massey University, \\ Private Bag 11 222, Palmerston North, New Zealand \\ ${ }^{2}$ Ravensdown Limited, Hornby, Christchurch, New Zealand \\ s.chok@massey.ac.nz
}

\begin{abstract}
Aerial topdressing using differential rate application technology improves fertiliser spreading on hill country farms. However, the system's ability to place fertiliser accurately and precisely within an area needs to be determined. Accuracy was determined by comparing measured and intended application rates. Precision was indicated by the coefficient of variation $(\mathrm{CV})$, which is the standard deviation of the measured application rate over the mean of this rate. Two trials were carried out, where aircraft deposited fertiliser at two application rates and fertiliser was captured using cone-shaped collectors. The average measured application rate for both trials was less than the intended rate. The CV ranged from 35 to $57 \%$, and was lower than CV's from pilot-operated hopper systems (78\%). A one-way analysis of variance test found the difference between measured application rate in the high and low application zone was statistically significant. The results indicate work is required to improve the accuracy and precision of the differential rate system, however, the system shows promise.
\end{abstract}

Keywords: differential rate application technology, aerial spreading, fertiliser placement

\section{Key messages}

- Aerial differential rate application improved application precision as indicated by the coefficient of variation when compared to pilot-operated hopper doors

- Results indicate a significant difference between two application zones

- Work is on-going to improve precision and accuracy of application within the fertiliser application zone.

\section{Introduction}

Aerial topdressing using differential rate application technology (DRAT) utilises GPS (global positioning system) technology to facilitate computer-controlled operation of hopper doors based on aircraft position. It enables controlled fertiliser placement on hill country farms, resulting in improved nutrient management. Currently, for the most part, fertiliser is applied over hill country farms at a single blanket rate. This is not ideal for optimising pasture production because soil fertility varies over an area (Morton et al. 2000). DRAT allows farmers to apply fertiliser to specific zones to optimise pasture production.

Ravensdown Limited offers farmers a differential rate application system for aerial fertiliser spreading. The accuracy and precision of this DRAT system of placing fertiliser on the ground was evaluated in this paper. Accuracy was determined by the difference between the measured and the intended application rate. Precision was determined by calculating the coefficient of variation; the standard deviation of the measured application rate over the mean of this rate. A study by Grafton et al. (2012) showed that a DRAT system could reduce the coefficient of variation (CV) from 78 to $42 \%$. Ravensdown Limited aims to achieve a CV of 30 to $35 \%$.

Studies of DRAT system capability for aerial fertiliser placement on hill country farms are scarce, especially those using ground data collection to validate the application rate. The objective of this paper was to assess the capability of the DRAT system described above, explain the methodology for collecting spatially related data and to present the steps taken to improve the differential rate system.

\section{Methods}

\section{Collectors}

Collectors covered an area of $0.5 \mathrm{~m}^{2}$ and were composed of 3 parts: metal stand, cone and collar (Figure 1). A total of 179 collectors were available.

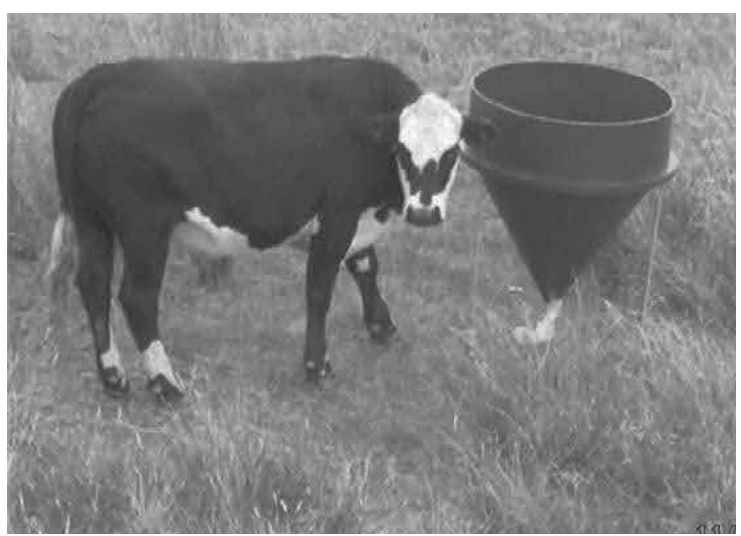

Figure 1 A cow taking interest in a collector. 
High speed photometry taken of a single collector as fertiliser was applied by aircraft, showed that some fertiliser particles bounced out of the collector. Three slow motion videos were analysed for both superphosphate and urea. Analysis consisted of manually counting the number of particles falling in and bouncing out of the collector. The average ratio of particles bouncing out was used to correct collected data (Table 1).

\section{Method}

Trials were carried out at Limestone Downs, Port Waikato (February 2014) and Longview, Waitotara (April 2015) to collect ground truth data. Ground truth trials determine if the fertiliser placement and mass collected on the ground is a reflection of the application rate intended by the aircraft. A Pacific Aerospace Cresco 600 aircraft applied the fertiliser in both trials.

\section{Trial 1}

Limestone Downs is a coastal hill country farm with highly variable topography. A grid formation was used to place each collector $70 \mathrm{~m}$ apart (Figure 2). The grid had 11 by 11 collectors and covered 61 ha. This pattern for collector placement was deemed sufficient to capture differences between application zones. The original design used 141 collectors but some were excluded as they were inaccessible or because of the presence of stock. A total of 136 collectors were used; of these, 35 were placed in groups of five throughout the trial area with four collectors in a square, each $5 \mathrm{~m}$ from a central collector. These were used to determine spatial variance.

Due to challenging topography and limited labour, collectors were set up over 2 days with fertiliser application taking place on the third day. Between the second and third day, rain water collected in some sample bags while others acquired holes made by insects and wild turkeys. Twenty six collectors were affected with five samples being unrecoverable.

Outside the $250 \mathrm{~kg} / \mathrm{ha}$ application zone, $500 \mathrm{~kg} / \mathrm{ha}$ of superphosphate was applied (Figure 2). Wind data were not recorded on the application day, but conditions were considered windy.

Table 1 Percentage of urea and superphosphate particles that bounced out of the collector.

\begin{tabular}{lcccc}
\hline & \multicolumn{2}{c}{ Particles bouncing out (\%) } & \\
\cline { 2 - 4 } Fertiliser type & Video 1 & Video 2 & Video 3 & Average \\
\hline Urea & 12.50 & 26.98 & 8.00 & 15.83 \\
Superphosphate & 8.56 & 4.08 & 4.55 & 5.73 \\
\hline
\end{tabular}

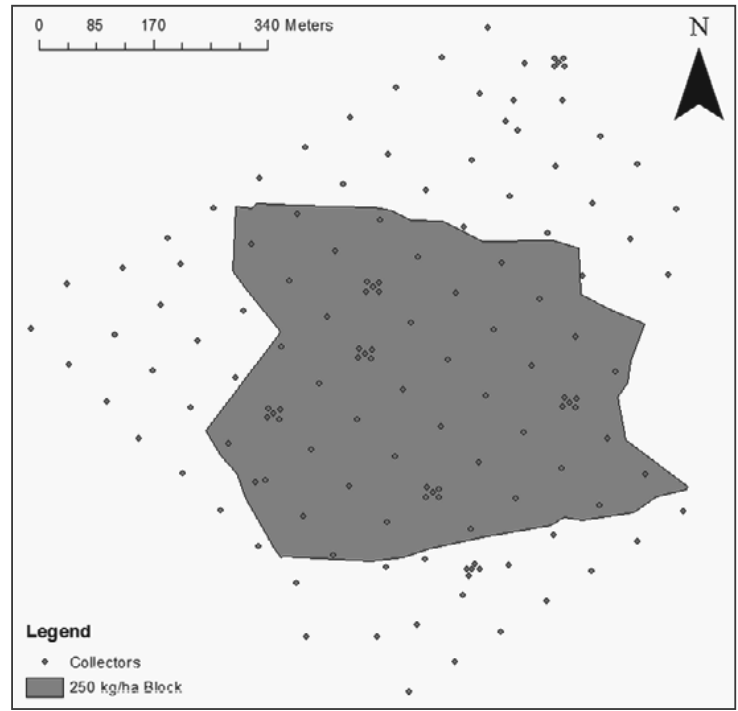

Figure 2 Final collector placement at Limestone Downs.

\section{Trial 2}

Time and labour investments in ground truth trials were large, limiting how and where collectors were placed. Limestone Downs' grid pattern covered a large area, but did not provide data on all three levels of variation in aerial topdressing. This variation was:

- Between two application zones. This was desired because it shows the DRAT system was capable of varying the application rate

- Between two flight paths/swath width. A non-GPS aircraft was more likely to double spread or miss areas because pilots rely on physical landmarks to reference their flight path (Ballard \& Will 1971). In contrast, DRAT records the aircraft's position and accounts for the swath width

- Within a swath width. Variability at this level was attributed to wind conditions and aircraft speed.

A nested grid sampling design allowed these variations to be measured. This design was undertaken at Longview, where a blend of phosphorus, sulphur, nitrogen and trace elements was applied, rather than pure superphosphate. This meant the collected ground data could not be fully corrected using the particle bouncing out ratio. However, $89.5 \%$ of the collected mix was composed of superphosphate, urea and similar sized compounds containing sulphur (e.g. maxi sulphur super), so the effect of the other fertiliser types (e.g. trace elements) on the amount of fertiliser in a collector was likely to be small. Longview is predominantly flat with sand dunes being the main topographical variation. Collectors were placed 5, 25, 50 and $150 \mathrm{~m}$ from each other in a branching configuration (Figure 3). The configuration was achieved by laying out a $3 \times 3$ collector grid over the trial site, with each collector 150 $\mathrm{m}$ apart. From each of these, two collectors were placed 


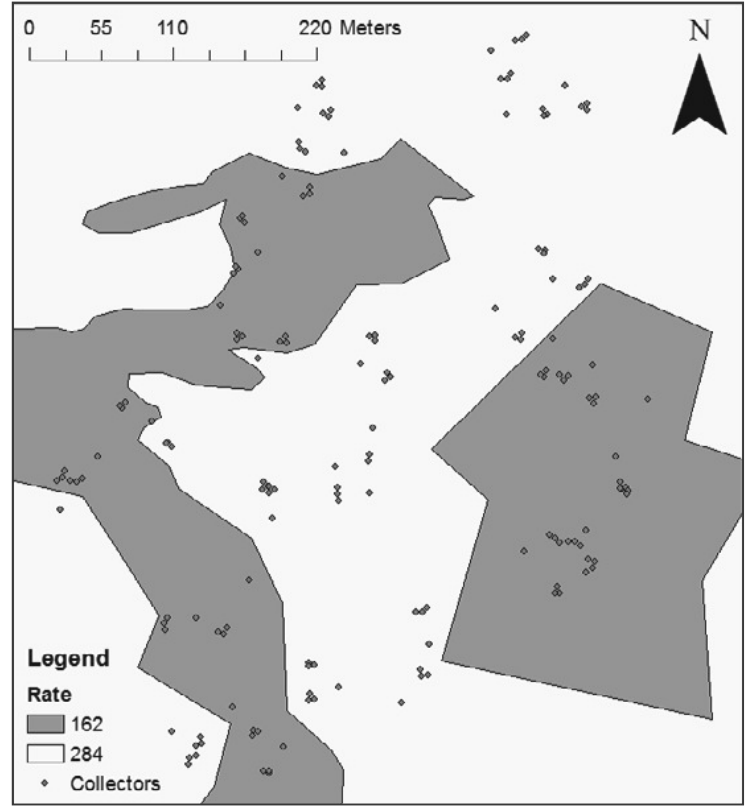

Figure 3 Final collector placement at Longview.

$50 \mathrm{~m}$ away and so on, with their direction determined using a random number generator.

In total, 165 collectors were positioned over a 30 ha area. The collectors were set up over two days without sample bags attached. Due to rainfall, some collectors were not fully dried before attaching the sample bag and 23 samples (14\%) were unrecoverable. The two fertiliser rates used were 162 and $284 \mathrm{~kg} / \mathrm{ha}$. Wind velocity and direction were measured using an anemometer. The average wind velocity was $0.9 \mathrm{~m} / \mathrm{s}$ in a north-easterly direction, ranging from 0.17 to $1.97 \mathrm{~m} / \mathrm{s}$.

\section{Results and Discussion}

The measured application rate for the Limestone Downs and Longview trials were less than intended for the high and low application zones (Table 2). High application zones experienced greater deviation from the intended application rate than did the low application zones. One possible explanation for the reduced application rate was that the aircraft hopper door was too narrow.

At Limestone Downs, the flow rate was calibrated on-farm just before the trial. GPS and swath width were used to determine the application area covered by a single load (approximately 2 tonnes) and the rate was adjusted to meet application requirements. Since the application rate on the ground was less than expected, this suggests that factors such as topography and changes in wind conditions could have affected fertiliser placement. Calibration of hopper flow rate to the application rate did not occur at Longview.

A one-factor analysis of variance (ANOVA) test, comparing the effect of collector distance on application rate at Longview, showed that the means were not significantly different. This suggests that the variation within a group of data points was similar to the variation between the groups (Table 3). Therefore,

Table 2 Statistical data for the Limestone Downs and Longview trials.

\begin{tabular}{lcccc}
\hline & Limestone Downs & \multicolumn{2}{c}{ Longview } \\
\hline Intended application rate (kg/ha) & 500 & 250 & 284 & 162 \\
Average measured application rate (kg/ha) & 308.0 & 203.4 & 198.4 & 120.3 \\
Difference between intended and measured average rate (\%) & 38.4 & 18.6 & 30.1 & 25.7 \\
Standard Deviation (kg/ha) & 174.4 & 103.0 & 68.8 & 63.8 \\
CV (\%) & 56.7 & 50.6 & 34.7 & 53.0 \\
\hline
\end{tabular}

Table 3 Summary and ANOVA on collector placement distance for Longview.

\begin{tabular}{lcccc}
\hline Groups & Count & Sum & Average & Variance \\
\hline $5 \mathrm{~m}$ & 76 & 12316.72 & 162.0621 & 5640.565 \\
$25 \mathrm{~m}$ & 37 & 5709.571 & 154.3127 & 8396.464 \\
$50 \mathrm{~m}$ & 19 & 3108.874 & 163.625 & 4563.783 \\
$150 \mathrm{~m}$ & 10 & 1489.572 & 148.9572 & 2454.15 \\
\hline
\end{tabular}

\section{ANOVA}

\begin{tabular}{lccccc}
\hline Source of Variation & SS & df & MS & F & P-value \\
\hline Between groups & 2925.115 & 3 & 975.0384 & 0.162203 & 0.9216275 \\
Within groups & 829550.5 & 138 & 6011.235 & & 2.670203 \\
Total & 832475.6 & 141 & & & \\
\hline
\end{tabular}




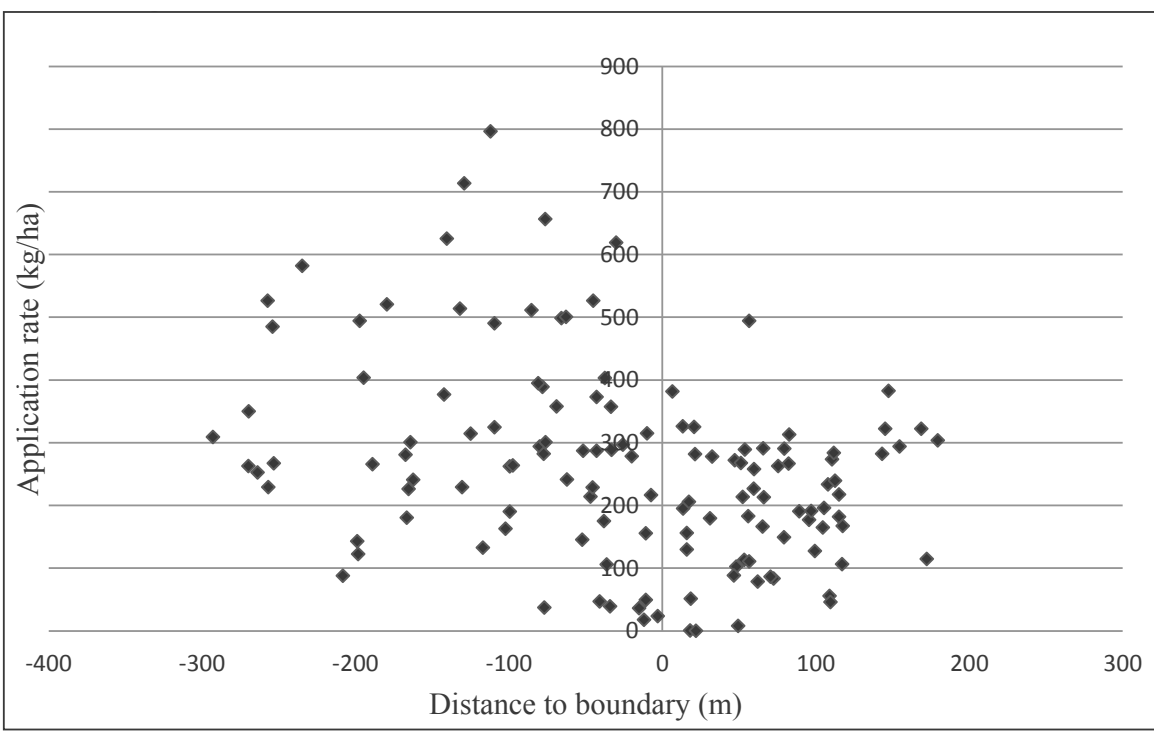

Figure 4 Comparison of application rate with the collector's proximity to the nearest treatment boundary line for Limestone Downs. A positive distance means the collector is in the 250 $\mathrm{kg} / \mathrm{ha}$ application zone.

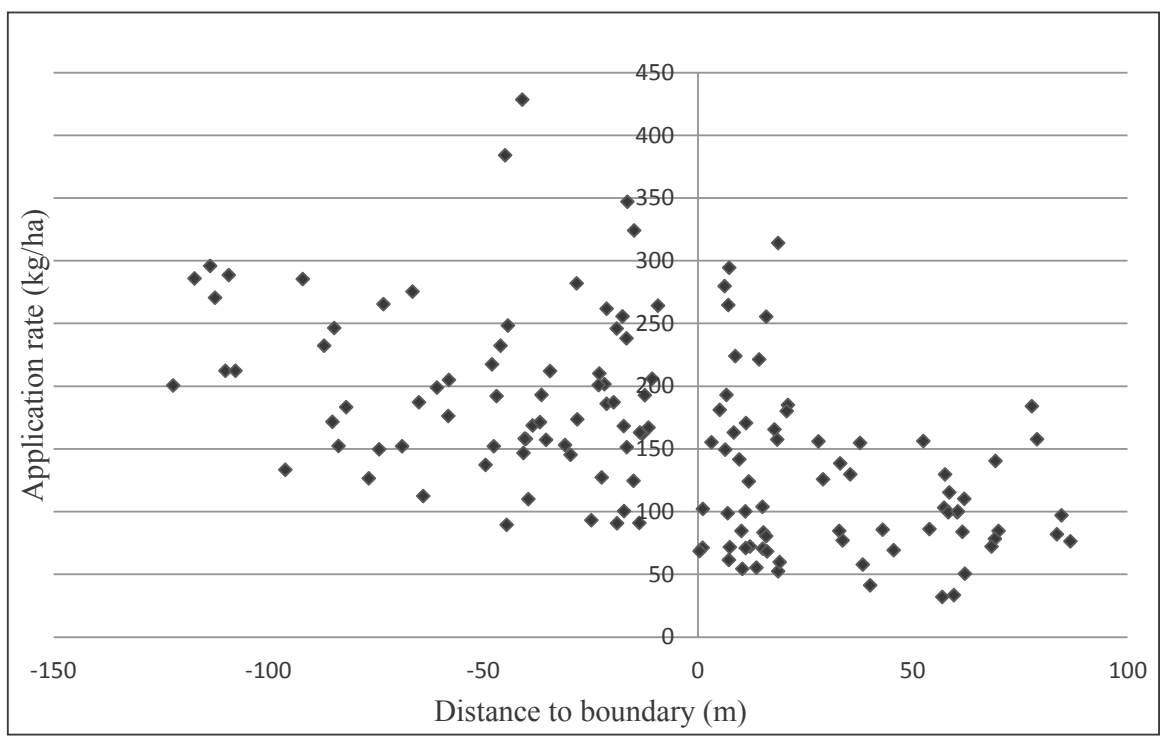

Figure 5 Comparison of application rate to the collector's proximity to the nearest treatment boundary line for Longview. A positive distance means the collector was within the 162 $\mathrm{kg} / \mathrm{ha}$ application zone.

all groups experienced the same variation, such as changes in wind velocity and direction. Variations caused by wind conditions are uncontrollable and have been shown by Macfarlane et al. (1987) and Barker (1979) to significantly impact the transverse spread pattern. Wind was a likely contributor to differences in the intended and measured application rates reported here. Fertiliser spreading in little or no wind reduces variation, but these conditions occur infrequently in New Zealand hill country.

Figures 4 and 5 compare the application rate with the proximity of the collectors to the nearest treatment boundary line for Limestone Downs and Longview, respectively. A positive distance indicates the collector was within the low application zone, while a negative distance means the collector was within the high application zone. A large variation in the application rate was expected close to the treatment boundary line $(\mathrm{x}=0)$, as the hopper door changes position. When the collector was further away from the boundary line, the application rate should vary around the new average.

The precision of data points in the 500 $\mathrm{kg} / \mathrm{ha}$ zone at Limestone Downs was low. It had the largest standard deviation of 174 $\mathrm{kg} / \mathrm{ha}$ and the variability was observed in the wide spread of points on the left side of the y-axis (Figure 4). The standard deviation improved in Longview's trial with a reduction in standard deviation of 38 to $60 \%$ when compared to Limestone Downs.

It is noted, however, that the geography and wind conditions for the two trial sites were different and conclusions from single data results should be made with care.

It would be beneficial to replicate trials at Longview and Limestone Downs for different wind conditions and to determine reproducibility. However, this is unlikely to occur because of time and resource constraints.

Collector data for Longview's $284 \mathrm{~kg} / \mathrm{ha}$ zone had the lowest $\mathrm{CV}$ at $35 \%$, while the other areas were in the low to mid-fifties. All CVs were lower than those reported 
by Grafton et al. (2012) and Murray (2007) (63-78\%) when the hopper was pilot-operated. Therefore, the DRAT system does reduce the CV of aerial fertiliser application. Improvements to the $\mathrm{CV}$ and standard deviation can be made by ensuring an appropriate swath width and flight pattern is used. However, wind speed and direction will continue to be a limitation to the DRAT system's precision. The current collection method attempts to estimate the transverse spread pattern but could be improved to get a better indication of the ground application rate.

An ANOVA test for Limestone Downs and Longview showed there was a highly significant $(\mathrm{P}<0.001)$ difference in application rate between the high and low application zones for both trials. This indicates that the DRAT system is able to recognise the treatment separation line and apply two different application rates.

Improvements to the DRAT system are continuously being made. Recently, improvements were made to the precision of the DRAT system hopper opening on entry into a fertiliser application area, and better accounting for the forward motion of particles when exiting an application zone. This will likely improve the ground application rate near boundaries. Further calibration between hopper flow rate and application rate is underway. Another trial to collect fertiliser placement data is planned for this year. The method of collecting data will be improved so that a transverse spread pattern can be captured and errors minimised. Collectors will also be re-designed so that they can catch all fertiliser particles. Design options include cloth catchers as used by Lockett (1998) and larger plastic bags.

\section{Conclusion}

The measured application rates from both Limestone Downs and Longview were lower than the intended rate. The CV for Limestone Downs and Longview was an improvement over pilot- operated hopper door systems, although it has not consistently reached the goal of 30 $-35 \%$. There was a significant difference between the measured application rate in the low and high zone in both trials. Although the DRAT system tested did not meet all expectations for precision and accuracy, it has improved the CV obtained over that obtained from a pilot-operated hopper system, and was able to apply differential fertiliser rates. Sampling methodologies will also be improved for the next trial to reduce error. Ravensdown will continue research to improve the accuracy and precision of fertiliser placement from fixed wing aircraft.

\section{ACKNOWLEDGEMENTS}

The authors acknowledge Ravensdown Limited for their funding and continued support of this project. We thank the Alma Baker Trust and Alf Harwood of Limestone Downs and David Pearce, the owner of Longview, for allowing these trials to be carried out on their properties.

\section{REFERENCES}

Ballard, R.; Will, G. 1971. Distribution of aerially applied fertiliser in New Zealand forests. New Zealand Journal of Forestry Science 1: 50-59.

Barker, P. R. 1979. Factors affecting aerial distribution of fertilizers to forests. In: Proceedings of the forest fertilization conference. Alderbrook Inn, Union, Washington.

Grafton, M.; Yule, I.; Watson, R. 2012. Improving the field $\mathrm{CV}$ of aerial topdressing; through computer controlled prescription delivery. http://elibrary.asabe. org/abstract.asp? aid $=41974 \& \mathrm{t}=5$

Lockett, E. 1998. A new system for evaluating the distribution of aerially spread material. Tasforests Hobart 10: 83-90.

Macfarlane, M.; Korte, C.; Gillingham, A. 1987. The effect of increasing winds on the distribution of oversown seed and fertiliser. Proceedings of the New Zealand Grassland Association 48: 131-136.

Morton, J.; Baird, D.; Manning, M. 2000. A soil sampling protocol to minimise the spatial variability in soil test values in New Zealand hill country. New Zealand Journal of Agricultural Research 43: 367375.

Murray, R. I. 2007. Variable rate application technology in the New Zealand aerial topdressing industry. DPhil thesis. Massey University, New Zealand. 
